\title{
Apical Right Ventricular Hypertrophic Cardiomyopathy-A Case Report
}

\author{
Ramachandran Muthiah \\ Thoothukudi Medical College Hospital, Thoothukudi, India \\ Email: cardioramachandran@yahoo.co.uk
}

Received 4 January 2016; accepted 21 February 2016; published 24 February 2016

Copyright (C 2016 by author and Scientific Research Publishing Inc.

This work is licensed under the Creative Commons Attribution International License (CC BY). http://creativecommons.org/licenses/by/4.0/

c) (i) Open Access

\begin{abstract}
A relatively infrequent form of hypertrophic cardiomyopathy is the isolated apical variant and it is more common in oriental people, especially in the Japanese. It contributes $25 \%$ of cases of hypertrophic cardiomyopathy in Japan but only $1 \%$ to $2 \%$ in the non-Japanese population. It may occasionally present in the elderly and classically involve the apex of the left ventricle. An isolated apical right ventricular involvement had been detected in an elderly female by transthoracic twodimensional echocardiographic imaging.
\end{abstract}

\section{Keywords}

\section{Asymmetric Apical Hypertrophy, Right Ventricle, Echocardiography}

\section{Introduction}

Cardiomyopathy is a chronic and sometimes progressive disease in which the heart muscle (myocardium) is abnormally enlarged, thickened and/or stiffened. The second most common form of heart muscle disease is hypertrophic cardiomyopathy and it is characterized by the abnormal growth and arrangement of muscle fibers in the heart (myocardial disarray), leading to excessive thickening of the heart walls. Typically, the portion of the muscle mass that is thickest is in the heart's main pumping chamber (left ventricle) with the muscle wall that separates the heart's chambers (septum) affected most often. This condition is referred as “asymmetric septal hypertrophy”.

The distribution of muscle thickness (hypertrophy), location, and degree of wall thickness may vary greatly among patients. In symmetric ventricular hypertrophy, the thickening is evenly distributed throughout the ventricle including the septum and wall. In apical hypertrophy, the thickening is localized at the bottom portion of the heart. The histologic hallmark of hypertrophic cardiomyopathy is a triad of myocyte hypertrophy, myocyte disarray, and interstitial fibrosis. The myocyte disarray also occurs in aortic stenosis and long standing hyper- 
tension. The presence of extensive disarray (more than $10 \%$ of ventricular septal myocytes) is a highly specific marker of hypertrophic cardiomyopathy.

The apical hypertrophic cardiomyopathy usually involves the apex of the left ventricle and rarely involves the right ventricular apex or both [1]; historically, it is thought to be confined to Japanese population. Its prevalence in Japan was 15\%, whereas in USA the prevalence was only 3\% [2]. A transthoracic echocardiography is the initial diagnostic tool in the evaluation of apical hypertrophic cardiomyopathy.

Apical variant of hypertrophic cardiomyopathy isolately involving the right ventricular apex is uncommon and so this case had been reported.

\section{Case Report}

A 60-year-old elderly woman was referred for screening echocardiographic evaluation as a routine medical check-up. She had no complaints of dyspnea, chest pain or palpitation and no family history of sudden cardiac death. The pulse rate was $76 \mathrm{bpm}$ and the blood pressure was 130/70 mmHg. Physical examination revealed no abnormal findings. Blood chemistry, X-ray chest and ECG were normal. On two-dimensional echocardiography, an apical 4-chamber view of the right ventricle revealed hypertrophy of the apex in an "ace-of-spades" configuration and an increased asymmetric thickness of the right ventricular apex $(36 \mathrm{~mm})$ suggesting the diagnosis of apical right ventricular hypertrophic cardiomyopathy in the image given below as in Figure 1. Color Doppler evaluation showed no abnormal findings.

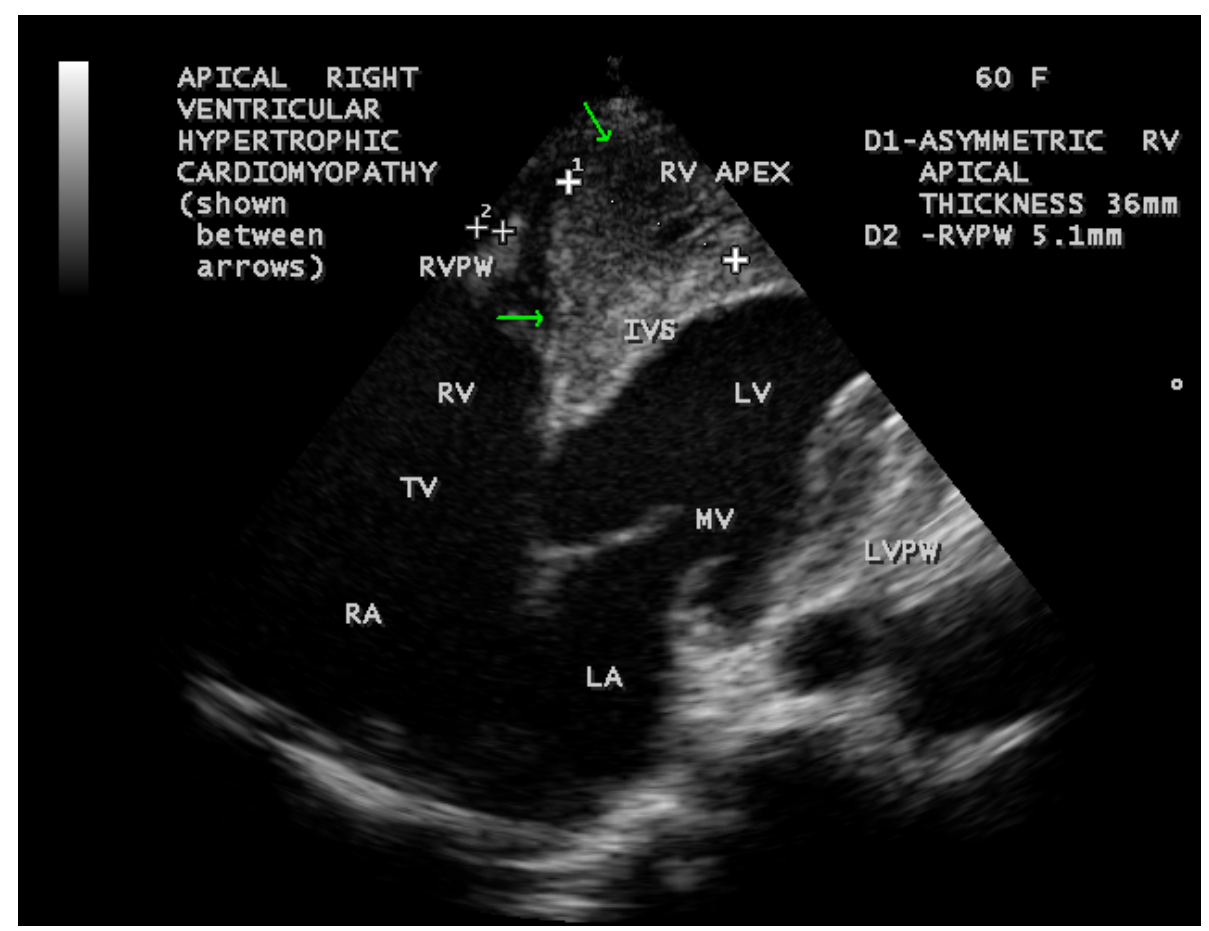

Figure 1. 2D echocardiagraphic image (apical 4 chamber view).

Screening of family members revealed no abnormality. Since she was asymptomatic, no further investigation or particular treatment for this condition was preferred and advised periodic follow up.

\section{Discussion}

Hypertrophic cardiomyopathy (HCM) affects up to 500,000 people in the United States accounting for less than $10 \%$ of all cases. The cause of HCM is largely unknown but most cases appear to be genetic in origin. HCM shows variable clinical presentation, prevalence, morphology and prognosis depending on the race. Apical hypertrophic cardiomyopathy was first described in Japan and it had been regarded as an atypical phenotype of non-obstructive HCM. The apical HCM is frequently sporadic; however, a few families have been reported with 
autosomal dominant inheritance [3]. A sarcomere gene mutation (E101K mutation in the alpha-cardiac actin gene) had been identified in these families. A family history is more common in patients with asymmetric septal hypertrophy than with apical hypertrophic cardiomyopathy.

Morphologically apical HCM is divided into 3 types; pure focal, pure diffuse and mixed, of which pure focal is most common [4]. Others have divided the apical hypertrophic cardiomyopathy (AHCM) into two groups, based on whether they had isolated asymmetric apical hypertrophy (pure AHCM) or had co-existent hypertrophy of the interventricular septum (mixed AHCM) [5].

In contrast to left ventricular pathology in HCM, the involvement of the right ventricle is uncommon occurring in up to $15 \%$ of patients. Histologic findings appear to be similar to those in the left ventricle, suggesting similar pathogenesis [6]. Isolated hypertrophic obstructive cardiomyopathy of the right ventricle had been reported without any involvement of the interventricular septum or left ventricle [7].

The mean age of presentation of apical HCM is $41.4 \pm 14.5$ years and is most commonly seen in males. About $54 \%$ of patients with apical HCM are symptomatic and the most common presenting symptom is chest pain, followed by palpitation, dyspnea and syncope. Physical findings of fourth heart sound and a new murmur may be present. The most frequent ECG findings are negative T-waves in the precordial leads. "Giant T-wave inversion" (depth > $10 \mathrm{~mm}$ ) and loss of septal Q waves should raise strong suspicion of apical HCM and are found in $47 \%$ of cases. This case was asymptomatic with no family history, no physical findings and had a normal ECG.

Echocardiography has been universally accepted as the initial imaging modality in investigation of patients with apical HCM. Wall thickness of the right ventricle can be measured by two-dimensional echocardiography and more than $12 \mathrm{~mm}$ denotes severe hypertrophy [8]. The diagnostic criteria for apical hypertrophic cardiomyopathy included demonstration of asymmetric hypertrophy, confined predominantly in the apex, with an apical wall thickness $\geq 15 \mathrm{~mm}$ and a ratio of maximal apical to posterior wall thickness $\geq 1.5 \mathrm{~mm}$, based on echocardiography [9]. This criteria was described to diagnose the apical left ventricular hypertrophic cardiomyopathy and it can be applied to diagnose the apical right ventricular hypertrophic cardiomyopathy, based on wall thickness. Massive hypertrophy (wall thickness $\geq 30 \mathrm{~mm}$ ) may be associated with high risk of sudden cardiac death [10]. In this case, asymmetric apical wall thickness of the right ventricle is $36 \mathrm{~mm}$ and its posterior wall is $5.1 \mathrm{~mm}$ and a ratio of maximal apical to posterior wall thickness $7.06 \mathrm{~mm}$, satisfying the diagnosis of apical right ventricular hypertrophic cardiomyopathy.

Echocardiographically, the wall thickness at the base of the heart is normal and the pathological thickness is seen asymmetrically towards the apex. The degree of thickness increases from base to apex resulting in a markedly diminished apical cavity and a spade-shaped [11] right ventricular cavity suggesting apical right ventricular hypertrophic cardiomyopathy in the apical 4 chamber view of two-dimensional echocardiographic image of this patient.

The prognosis of apical HCM is relatively benign. The overall mortality rate is $10.5 \%$. Some apical HCM patients may develop life threatening complications such as sudden cardiac death [12] which is more seen in asymmetric septal hypertrophy than apical HCM. High risk assessment must be done in all patients with apical HCM. Those having the risk factors such as syncopal episodes, arrhythmias, ventricular wall thickness $>30 \mathrm{~mm}$, family history of sudden death may benefit from ICD (implantable cardioverter defibrillator) placement. Beta adrenergic blocking agents are the first line therapy for symptomatic patients. Since the apical wall thickness of the right ventricle is $36 \mathrm{~mm}$ in this case, ICD placement is preferred if any life threatening complications on follow up. The patient was followed for one year and no such complications noticed.

\section{Conclusion}

Isolated apical right ventricular hypertrophic cardiomyopathy had been detected rarely as an incidental finding by $2 \mathrm{D}$ echocardiography at the age of 60 years in an elderly female in the tropical coastal region of Thoothukudi at the southern region of India.

\section{References}

[1] Albanesi Filho, F.M., Castier, M.B., Lopes, A.S. and Ginefra, P. (1997) Is the Apical Hypertrophic Cardiomyopathy Seen in One Population in Rio de Janeiro City Similar to That Found in the East? Arquivos Brasileiros de Cardiologia, 69, 117-123.

[2] Kitaoka, H., Doi, Y., Casey, S.A., Hitomi, N., Furuno, T. and Maron, B.J. (2003) Comparison of Prevalence of Apical 
Hypertrophic Cardiomyopathy in Japan and the United States. American Journal of Cardiology, 92, 1183-1186. http://dx.doi.org/10.1016/j.amjcard.2003.07.027

[3] Arad, M., Penas-Lado, M., Monserrat, L., Maron, B.J., Sherrid, M., Ho, C.Y., Barr, S., Karim, A., Olson, T.M., Kamisago, M., et al. (2005) Gene Mutations in Apical Hypertrophic Cardiomyopathy. Circulation, 112, 2805-2811. http://dx.doi.org/10.1161/CIRCULATIONAHA.105.547448

[4] Choi, E.Y., Rim, S.J., Ha, J.W., Kim, Y.J., Lee, S.C., Kang, D.H., Park, S.W., Song, J.K., Sohn, D.W. and Chung, N. (2008) Phenotypic Spectrum and Clinical Characteristics of Apical Hypertrophic Cardiomyopathy; Multicenter EchoDoppler Study. Cardiology, 110, 53-61. http://dx.doi.org/10.1159/000109407

[5] Erikson, M.J., Sonnenberg, B., Woo, A., Rakowski, P., Parker, T.G., Wigle, E.D. and Rakowski, H. (2002) Long Term Outcome in Patients with Apical Hypertrophic Cardiomyopathy. Journal of American College of Cardiology, 39, 638645. http://dx.doi.org/10.1016/S0735-1097(01)01778-8

[6] Radoslow Krecki, M.D. (2007) Involvement of Right Ventricle in Hypertrophic Cardiomyopathy. Circulation, 116, 2551-2555.

[7] Mittal, S.R. and Jain, S. (1998) Isolated Right Ventricular Hypertrophic Obstructive Cardiomyopathy. Journal of Association of Physicians of India, 46, 970-971.

[8] Mckenna, W.J., Kleinebenne, A., Nihoyannopoulos, P. and Foale, R. (1988) Echocardiographic Measurement of Right Ventricular Wall Thickness in Hypertrophic Cardiomyopathy. Relation to Clinical and Prognostic Features. Journal of American College of Cardiology, 11, 351-358. http://dx.doi.org/10.1016/0735-1097(88)90101-5

[9] Yusuf, S.W., Bathina, J.D., Banchs, J., Mouhayar, E.N. and Daher, I.N. (2011) Apical Hypertrophic Cardiomyopathy. World Journal of Cardiology, 3, 256-259. http://dx.doi.org/10.4330/wjc.v3.i7.256

[10] Kasirye, Y., Manne, J.R., Epperla, N., Bapani, S. and Garcia-Montilla, R. (2012) Apical Hypertrophic Cardiomyopathy Presenting as Recurrent Unexplained Syncope. Clinical Medicine and Research, 10, 26-31. http://dx.doi.org/10.3121/cmr.2011.986

[11] Feigenbaum, H., Armstrong, W.F. and Ryan, T. (2005) Cardiomyopathies. Feigenbaum's Echocardiography, 6th Edition, Chapter 17, 552.

[12] Yang, H.S., Song, J.K., Song, J.M., Kang, D.H., Lee, C.W., Hong, M.K., Kim, J.J., Park, S.W. and Park, S.J. (2005) Comparison of the Clinical Features of the Apical Hypertrophic Cardiomyopathy versus Asymmetric Septal Hypertrophy in Korea. Korean Journal of Internal Medicine, 20, 111-115. http://dx.doi.org/10.3904/kjim.2005.20.2.111 